\section{Interacionismo simbólico e movimentos sociais: enquadrando a intervenção}

Jordão Horta Nunes

Resumo: A teoria do quadro (frame), desenvolvida por Goffman em Frame Analysis (1974), tem sido aplicada na orientação estratégica e na metodologia de análise dos novos movimentos sociais. O objetivo aqui é reconstruir o emprego do conceito de frame e seus desdobramentos teóricos, bem como de outros elementos da tradição sociológica interacionista na elaboração, feita por autores como Gamson (1988), Snow e Benford (1988) e Johnston (2005), da fundamentação da análise da ação coletiva em movimentos sociais. Constata-se a fecundidade do frame da ação coletiva, não apenas na análise de mobilizações realizadas inicialmente com baixo grau de organização e fora da esfera institucional, mas também de estratégias empregadas por órgãos estatais ou programas sociais governamentais.

Palavras-chave: Movimentos Sociais, Análise do Frame, Erving Goffman, Ação Coletiva, Interacionismo Simbólico.

A nalisa-se, aqui, a contribuição da escola sociológica do interacionismo simbólico nas teorias dos movimentos sociais, desde a teoria do comportamento coletivo de Blumer, até a teoria do frame da ação coletiva, com destaque em autores como D. Snow e R. Benford, identificando suas potencialidades e limites na análise de mobilizações coletivas no mundo contemporâneo, em relação às teorias tradicionalmente reconhecidas no campo da pesquisa e organização da intervenção social.

Embora haja diferentes concepções de movimentos sociais na produção sociológica, é possível detectar um consenso nas reconstruções contemporâneas sobre o tema (e.g., ALONSO, 2009; GOHN, 2008; SNOW, SOULE \& KRIESI, 2004), em torno de características que seriam próprias de um movimento social. A primeira delas é a mobilização coletiva, identificada e explicada de diferentes formas nas diversas teorias dos movimentos sociais: comportamento coletivo, ação coletiva, redes, ação conjunta ou coordenada, etc. A segunda é reivindicar ou propor mudanças, ou seja, intervir na realidade social, com algum nível de organização. Evidencia-se, também, um caráter não institucional na ação efetivada, em alguma medida. Finalmente, a ação coletiva, para ser considerada movimento social, deve apresentar alguma continuidade temporal.
Recebido: 06.02.13 Aprovado: 13.03 .13

1. Professor Titular de Ciências Sociais da Universidade Federal de Goiás. E-mail: jordao.fchf. ufg@gmail.com 
Compartilhando, de algum modo, esses elementos, as teorias dos movimentos sociais são fundamentadas, desde seu início, nos anos 1970, até os dias de hoje, por princípios diferentes, ligados mais à estrutura ou ao macrossocial, à psicologia do comportamento social, à racionalidade estratégica, a dimensões culturais, simbólicas, expressivas ou identitárias. Angela Alonso, em artigo recente (2009), identifica três famílias de teorias dos movimentos sociais que emergiram a partir de 1970 e que hoje podem ser consideradas clássicas: a teoria de mobilização dos recursos (MCCARTHY \& ZALD, 1977), a teoria do processo político (TILLY, 1975) e a teoria dos novos movimentos sociais (TOURAINE, 1978; HABERMAS, 1981; MELLUCI, 1980, 2001). No entanto, pode-se reconstruir a gênese do conceito de movimentos sociais em autores que precedem em muito as teorias clássicas, bem como identificar discussões e incorporações teóricas mais recentes. Com objetivo inicial de analisar a influência do interacionismo simbólico nas teorias dos movimentos sociais, identificaremos alguns antecedentes na teoria do comportamento coletivo de Blumer.

Blumer é o autor da mais célebre formulação dos princípios do Interacionismo Simbólico (doravante IS), reproduzida na maioria dos compêndios escolares e livros de introdução à perspectiva (e.g., LINDESMITH, STRAUSS \& DENZIN, 1988; CHARON, 1979; STONE \& FARBERMAN, 1970). No ensaio "The methodological position of Symbolic Interactionism" (1969, p. 1-60) Blumer, declarando-se sobretudo fiel ao pensamento de George Herbert Mead, que considera o principal responsável por estabelecer os fundamentos da abordagem, enuncia as premissas básicas do IS, que supõe constituírem um quadro comum, uma visão geral no estudo da vida humana em grupo, compartilhada por Mead, Dewey, Thomas, Znaniecki, Baldwin, Redfield e Wirth: os seres humanos agem com as coisas com base nos sentidos que as coisas apresentam para elas; essas "coisas" incluem tudo que os seres humanos podem perceber no mundo, como objetos físicos, categorias de objetos, instituições, ideais, atividades e situações; o sentido dessas coisas é derivado ou emerge da interação social que temos com nossos semelhantes; esses sentidos são manipulados e modificados por um processo interpretativo, usado pela pessoa ao lidar com as coisas que ela encontra (cf. NUNES, 2005, p. 25-6). Embora essa formulação, que constitui o que Lakatos (1978, p. 47) designaria como "heurística positiva" da escola interacionista, tenha sido expressa quando já havia um programa de pesquisa orientado por esses princípios metodológicos, implicando um certo consenso a respeito do quadro conceitual da perspectiva, há indícios de sua influência metodológica já no capítulo "Comportamento coletivo", que Blumer escreveu para uma coletânea editada por Robert Park e utilizada na formação sociológica dos alunos de graduação na Escola de Chicago (An Outline of the Principles of Sociology, 1940). 
Na teoria blumeriana do comportamento coletivo, o motor de fenômenos sociais coletivos desde a explosão incontrolável de uma multidão num estádio de futebol, até a ação coordenada de movimentos sociais ambientalistas como o Greenpeace, é um estado de inquietação social (social unrest). Porém o comportamento de uma manifestação como um linchamento exemplifica um comportamento coletivo elementar, uma interação caracterizada pela "reação circular", em que os indivíduos refletem, como numa forma de contágio, o estado sentimental de outros, dessa forma amplificando esses sentimentos. Essas formas de agrupamentos coletivos, como a multidão, o público e a massa são "elementares, naturais e espontâneas, emergindo sob certas circunstâncias ajustadas" e operam "fora de um arcabouço governante de regras e da cultura" (1939, p. 253). Já os movimentos sociais são vistos como "empreendimentos coletivos para estabelecer uma nova ordem de vida" (id., p. 255). Blumer vê os movimentos sociais como processos com origem na insatisfação com a forma de vida, de início espontâneos e mal organizados mas que, em seu desenvolvimento, adquirem uma cultura e uma organização social, com regras e valores, uma liderança estabelecida e uma divisão de trabalho duradoura. Assim, o movimento social constitui o final de um processo caracterizado por mudanças de valores graduais e convincentes, "que podem ser chamadas de tendências culturais [cultural drifts]" (id., p. 256). Influenciado pela ontogênese do self que Mead elabora em Mind, self and society (1932), Blumer enfatiza a necessidade de ver o movimento social de uma perspectiva temporal e evolutiva:

Em seu início, um movimento social é frouxamente organizado e caracterizado pelo comportamento impulsivo. Não tem objetivo claro; seu comportamento e pensamento estão principalmente sob a dominância da inquietude e da excitação coletiva. Assim que um movimento social se desenvolve, entretanto, seu comportamento, que originalmente foi disperso, tende a se tornar organizado, solidificado e persistente. É possível delinear aproximadamente estágios na carreira de um movimento social que representam essa organização crescente. (1939, p. 259)

A explicação blumeriana dos movimentos sociais está ligada a uma teoria do comportamento coletivo geral direcionado à mudança ou à intervenção social, que adquire, no curso de sua evolução, um caráter societário, passando a merecer o atributo de movimento social. No entanto, Blumer distingue três tipos de movimentos sociais: gerais, específicos e expressivos. Na trajetória de todos, está o estado de inquietude social na origem, a progressiva transformação cultural de valores e a crescente organização. No tipo geral, identificamos algumas tendências culturais na história contemporânea, como a valorização 
da educação e o cuidado com as crianças, que acarretam novas concepções do self aos agentes sociais, que passam a adquirir novas disposições e interesses e a terem suas condutas orientadas em certo sentido. Quando ocorre uma cristalização desses motivos para insatisfação e uma reorientação do self diante de novos anseios e desejos, focalizando e objetivando esse tipo de motivação, estamos diante das condições para a emergência de um movimento social específico, caracterizado pelo desenvolvimento de uma liderança reconhecida e de um modo de afiliação que envolve a consciência do coletivo (we-consciousness), articulada por um conjunto de regras e valores, além de um corpo geral de expectativas. Pode-se dizer que, no nível de movimento social, a ação coletiva toma o lugar do comportamento coletivo.

Blumer considera os movimentos "reformistas" e "revolucionários" como principais instâncias de movimentos sociais específicos, que apresentam objetivos definido e metas a serem alcançadas. Entretanto, sua análise não valoriza, como ocorreria quase quarenta anos depois na família de teorias de mobilização de recursos (TMR), a organização racional do movimento como resultado de cálculo racional entre benefícios e custos. Segundo essa perspectiva, a ação coletiva só se viabilizaria na presença de uma coordenação efetiva de ativistas e apoiadores e da organização dos recursos materiais (financeiros e infraestrutura). Ainda que a TMR e a teoria dos movimentos sociais como comportamento coletivo organizado socialmente priorizem a análise de como ocorre o processo de constituição do movimento, ou seja, os meios e mecanismos e não suas causas ou razões, Blumer, prenunciando o repertório conceitual do interacionismo simbólico, valoriza epistemologicamente a situação social. Ao analisar, por exemplo, a importância da agitação no movimento social, como "meio de excitar as pessoas e despertar nelas novos impulsos e idéias que as tornam inquietas e insatisfeitas" (1939, p. 260), o autor considera dois tipos de situação social. A primeira, marcada por abuso e discriminação injusta, mas em que os agentes envolvidos consideram natural a situação e não a questionam. Nessa situação, o papel do agitador é levá-los a desafiar e questionar seu próprio modo de vida, criando a inquietude social onde ela não ocorria. Em outra situação, as pessoas já estão alertas, inquietas e descontentes, mas são muito tímidas para agir ou não sabem o que fazer. Aqui o agitador deve intensificar, liberar e orientar as tensões que os agentes já experimentam. Há um perfil de self e uma modalidade de perfomance correspondente que seriam adequados ao agitador em cada uma das situações.

Blumer emprega, nessa passagem de seu ensaio, embora ainda de forma precária e incipiente, um conceito básico do interacionismo simbólico: definição da situação. Sua primeira formulação está em The Unadjusted Girl, de William Thomas: "Antes de qualquer ato de comportamento autodeterminado há 
sempre um estágio de exame e deliberação que podemos chamar de definição da situação. Na realidade não só os atos concretos são dependentes da definição da situação, mas toda uma conduta de vida e a personalidade do próprio indivíduo derivam, gradualmente, de uma série de tais definições" (1923, p. 42, destaque do autor). Uma situação pode ser caracterizada pelo enquadramento de tipos de conduta socialmente reconhecidos a posições ou atribuições funcionais, num processo interativo. Sob um ponto de vista metodológico, essa caracterização da situação parece similar à que fornece as teorias culturalistas dos papéis e status sociais (e.g., LINTON, 1938). Contudo, trata-se de uma concepção mais dinâmica, que ressalta o processo de construção dos papéis, tendo em vista as atitudes e o desempenho em situações interativas. A situação é vista como manipulável pelos agentes, por meio de estratégias de representação e condução da aparência; os indivíduos e grupos têm um papel ativo na constituição de suas personalidades e posições de status. Por outro lado, sempre que os participantes numa situação social compartilham uma mesma definição, a coordenação é facilitada e isso é fundamental para o êxito dos movimentos sociais.

A definição da situação, que pode ser considerada um processo cognitivo e social, está associada, na teoria do comportamento coletivo de Blumer, a outros processos construtivos, de ordem psicológica, filosófica e estratégica. Dentre os primeiros, está um tipo de envolvimento na situação, atingido pelo desenvolvimento de um esprit de corps (espírito de equipe) e o fortalecimento do estado de ânimo (morale). A dimensão filosófica consiste na construção de uma ideologia de grupo, incorporada em doutrinas, crenças e mitos, que devem ser reconhecidas subjetivamente, mas também possuir um apelo popular, para ser eficaz no movimento. Blumer conclui a caracterização dos movimentos sociais específicos ressaltando o papel da tática para obter e manter a adesão, bem como atingir os objetivos. As estratégias sempre dependem da natureza da situação em que o movimento está operando e sempre têm como referência o histórico cultural do movimento (BLUMER, 1939, p. 269).

O recurso metodológico à situação social seria empregado de forma mais profícua por outros interacionistas, como Goffman (2002 [1964]) e Lyman e Scott (1989). Influenciados pelo seminal artigo "Situated actions and vocabulary of motives", de Wright Mills (1940), admitiram a possibilidade de caracterizar linguisticamente uma situação, comparando "vocabulários" associados a determinados tipos de ações contextualizadas, o que deu origem a interessantes e profícuos desenvolvimentos, como a teoria sociológica dos motivos, mas também extensões na sociolinguística e nas ciências da cognição. Segundo Wright Mills, não há como atingir os estados mentais de outros, mas há uma forma empírica de dirigir investigações sociológicas sobre motivos, por meio da construção de vocabulários típicos latentes em situações e ações específicas: a variável é o 
vocabulário de motivos aceito, os extremos do discurso, em cada grupo dominante para a formação da opinião de um indivíduo. Robert Benford (1993), empregou dados produzidos numa pesquisa com duração de quatro anos sobre processos de mobilização em nível microssocial para recrutamento e participação em movimento social pelo desarmamento nuclear, identificou e elaborou quatro vocabulários de motivos que emergiram da interação entre os ativistas, patrocinadores, simpatizantes e outros significantes: severidade, urgência, eficácia e decência. Esses vocabulários forneceram aos atores razões convincentes para agir em prol do movimento ou de sua organização.

A fronteira com a psicologia social, principalmente com o behaviorismo social de Mead, marcou as análises dos movimentos sociais até os anos 1950 e 1960. A TMR, apesar de contrastar com a teoria do comportamento coletivo, por enfatizar a racionalidade estratégica em contraposição aos determinantes culturais, compartilhava com esta o enfoque micro. As outras duas famílias teóricas adotaram uma perspectiva macrossociológica e histórica e contestavam as explicações economicistas da ação coletiva. As teorias do processo político (TPP), cujo representante mais conhecido é o cientista social estadunidense Charles Tilly, não priorizam a escolha racional e a estratégia na constituição do movimento social, mas a "estrutura de oportunidades políticas", um conjunto de subsídios ou constrangimentos políticos, que favorece ou restringe as possibilidades de escolha. A dimensão explicativa do cultural aparece na adequação entre os repertórios do movimento social, i.e., os tipos de recursos empregados para a ação política (passeatas, listas de assinaturas, declarações públicas, panfletagem, violência direta, etc.) e o contexto histórico social. Entretanto, o fator que estrutura propriamente o repertório de um movimento social para sua prática de "interação contenciosa" entre desafiantes e detentores do poder é o regime político.

A TMR e a TPP não valorizam a cultura como fator explicativo ou motivador dos movimentos sociais, mas a racionalidade da organização e a ação política. No caso da TPP, há proximidade com o cultural, mas este é dependente, como no caso dos repertórios de mobilização e contensão, do regime político e do contexto histórico-social. Há escassa licença epistemológica para a perspectiva interpretativa ou construcionista. São as teorias dos novos movimentos sociais (TNMS) que comportam condições epistemológicas mais favoráveis à compatibilidade com as teorias interacionistas dos movimentos sociais, inclusive as teorias do frame da ação coletiva ou do protesto. Acata-se, nesse aspecto, a posição de Angela Alonso, admitindo que as teorias dos novos movimentos sociais, embora não evidenciem uma coesão suficiente para serem consideradas escolas, do ponto de vista metodológico, compartilham "um ar de família" dentre seus principais teóricos: Alain Touraine, Jürgen Habermas e Alberto Melucci: "são todos críticos da ortodoxia marxista, mas mantêm o enquadramento macro-histórico 
e a associação entre mudança social e formas de conflitos. Nisso não diferem da TPP. A especificidade está em produzir uma interpretação efetivamente cultural para os movimentos sociais" (2009, p. 59). Dentre esses três autores, Habermas desponta como o que teve maior influência da escola interacionista, embora a tenha demonstrado sobretudo em suas primeiras obras, como A lógica das ciências sociais (1996 [1967]). Habermas remete a Anselm Strauss e sua compreensão da ação social a partir do contexto de uma sequência de interpretações; cada nova interpretação é uma imagem revisada do passado à luz de um futuro antecipado. Novas situações e eventos problemáticos exigem uma distinta aplicação de enunciados comunicativos, bem como o reconhecimento subjetivo relacionado a determinadas expectativas. Inversamente, mudanças no grupo de referência exigem uma adaptação a novas terminologias, dentro das quais as situações que envolvem o agente e sua própria identidade são objeto de uma nova interpretação (cf. HABERMAS, 1996, p. 260-1). Ao declarar que os processos sociais devem ser analisados em termos de mudanças de linguagem, concordando com Strauss e, retrospectivamente, com algo da teoria sociológica dos motivos, atrás comentada, Habermas demarca seu interesse sobre uma problemática, muito presente no interacionismo simbólico, que viria a desenvolver em profundidade nos capítulos I e III de A teoria da ação comunicativa: quais são as estruturas e regras básicas que todos devem dominar para aprender uma língua e se relacionar com o mundo, com outras pessoas, levando em conta intenções, desejos e sentimentos? (HABERMAS, 1984, 1987).

A teoria do frame goffmaniana influiu significativamente na metodologia de pesquisa sobre os movimentos sociais, a partir dos anos 1980. O quadro (frame) é um artifício que seleciona, segundo as intenções e perspectivas de um sujeito individual ou coletivo, aquilo que percebemos. Em Frame Analysis (1974), Goffman, influenciado por William James (1950), Schutz (1945), mas também pela análise que Gregory Bateson realizou da metacomunicação (1972), considera o frame como um guia que constrange a interpretação, constituindo também uma condição necessária para sua existência. Existe sempre uma ação subjacente ao quadro e que não é definida ou estruturada unicamente pelo seu objeto, mas também por técnicas que são socialmente reconhecidas, ou seja, por um contexto de uso. O enquadramento (framing) exige técnica e arte, é um artifício, ou artefato, que condiciona a percepção e a experiência. O frame do cinema, por exemplo, além de exigir uma técnica sofisticada para sua produção, requer um condicionamento cultural para sua recepção em salas e horários apropriados. Nas salas de exibição na Índia, por exemplo, é comum a manifestação ruidosa do público, que aplaude, assobia, canta e dança com os atores ou até joga moedas em direção à tela. Esse tipo de comportamento seria considerado inadequado em outros países. O construto do frame traz várias vantagens à análise dos movimentos sociais, por constituir uma perspectiva que permite 
articular posições epistemológicas outrora dispostas dicotomicamente, ainda que sem integrá-las ou superá-las, pois elas ainda são constitutivas de nossas práticas culturais, no mundo em que a ciência já participa, reflexivamente, não só da crítica, mas também da produção e do usufruto dessas práticas: criador e obra, produção e recepção, plateia e palco, produtor e público-alvo, ativista e potencial ativista a ser recrutado, pesquisador e interlocutor pesquisado.

No início dos anos 1980, iniciou-se uma crítica à tendência dominante nas teorias dos movimentos sociais em direção à sociologia organizacional e aos modelos de tomada de decisões com base em teorias da escolha racional, efetivando um giro, ou melhor, um retorno cultural na análise dos movimentos sociais, de certa forma retomando as raízes na fronteira com a psicologia social. Snow e Benford (1986) criticaram a "visão estática da participação" nas teorias sobre os movimentos sociais, encontrando, na análise do frame, elementos para identificar os fatores que contribuem para o sucesso dos movimentos. O modo em que um movimento social enquadra um problema é um dos indicadores da sua tendência para formar a opinião pública. Os quadros (frames) servem como "andaimes conceituais" para a construção de novas ideologias ou para modificar as atualmente existentes. Os quadros não estão fixados em padrões de conversação culturalmente assimilados; ao contrário, os ativistas e os afiliados num movimento social têm grande responsabilidade sobre o processo de enquadramento (cf. NUNES, 2004). Assim, a análise ex post dos obstáculos que limitam o potencial desenvolvimento de frames num dado contexto social transforma-se numa estratégia político-ideológica que interessa não somente à metodologia de pesquisa da intervenção social, mas também à própria organização dos movimentos sociais.

David Snow e Robert Benford tiveram experiência prática nos frames que analisaram ou de que participaram. Além de ostentarem uma produção significativa na pesquisa sobre movimentos sociais, participaram ativamente como ativistas e na organização de protestos e movimentos. Foram pioneiros na identificação das funções que um quadro da ação coletiva deve desempenhar, que já transcenderam o âmbito acadêmico e figuram na agenda prática dos movimentos sociais. A construção de um quadro da percepção aos potenciais afiliados ao movimento deve conter (SNOW \& BENFORD, 1988): o enquadramento diagnóstico, onde se apresenta uma nova interpretação dos assuntos ou eventos, com a intenção de mobilizar à ação; o enquadramento prognóstico, apresentando uma solução ao problema diagnosticado; o enquadramento motivacional, em que se tenta prover uma razão ou motivo para agir conjuntamente. Vários estudos empíricos subsequentes identificaram e analisaram vários tipos de enquadramento prognóstico que movimentos sociais específicos construíram e efetivaram, concluindo que, em geral, os movimentos tendem a identificar vítimas de uma 
tipo de injustiça e amplificar simbolicamente essa vitimização. Contudo, ainda que a injustiça seja um motivo muito comum na maioria dos frames de protesto, não se demonstrou empiricamente que em movimentos ligados à religião ou identidade seja indispensável trabalhar com a categoria de injustiça.

Em relação ao enquadramento prognóstico, ou seja, a "o que fazer" para solucionar a questão social, é mais difícil generalizar diante da multiplicidade de possíveis casos. Contudo, algumas pesquisas atestam que "a identificação de problemas e causas específicas tende a constranger o intervalo de possíveis soluções "razoáveis" e estratégias propostas" (SNOW \& BENFORD, 2000). Deve-se também atentar para o contrafactual, levando em conta que a organização de um movimento social se efetiva numa conjuntura em que se confrontam entidades como uma "indústria" dos movimentos sociais, seus oponentes (como o governo), a mídia e os expectadores, que frequentemente se posicionam "em cima do muro". Assim, a organização deve prever o discurso e os vocabulários de motivos dos oponentes, antes de planejar o conteúdo do frame. J. Zuo e Benford, que analisaram o movimento democrático chinês em 1989 detectaram que os estudantes, antecipando a estratégia do Estado de rotular o movimento como "contra revolucionário" e "agitador", empregaram um repertório tático que foi consistente com as tradicionais narrativas culturais chinesas, enfatizando valores como o autossacrifício e a devoção à comunidade (apud SNOW \& BENFORD, 2000). Finalmente, o enquadramento motivacional, que provê razões para a luta e o engajamento na ação coletiva, requer a identificação, construção ou ressignificação simbólica de vocabulários de motivos apropriados.

O emprego metodológico da teoria do frame à análise e organização de movimentos sociais é bastante profícuo. No próprio Frame Analysis, já há elementos que, empregados em nível metateórico, apresentam grande potencial heurístico na extensão de diversas teorias existentes sobre movimentos sociais. O primeiro deles é a propriedade de transformação dos quadros. As transformações em quadros são de dois tipos: modulações (keeyings) ou fabricações (fabrications). Realizamos uma modulação ${ }^{2}$ no quadro quando "organizamos a experiência em termos de outro domínio (universo de significado sustentado por uma atividade) da experiência vivida, conhecendo apenas o que está envolvido, ou quando criamos outros domínios para nós mesmos ou ainda subvertemos a credibilidade de um domínio para outros" (NUNES, 2004, p. 158-159). Podese, por exemplo, empregar a observação de uma sequência de fatos num intervalo de tempo e transformá-la numa narrativa falada, ou numa crônica, ou numa história em quadrinhos. No frame da ação coletiva, uma petição coletiva pode ser realizada da forma tradicional, por lista de assinaturas em papel, mas também por mensagens de correio eletrônico ou chamadas telefônicas. Uma manifestação de repúdio, como outro exemplo, pode ser "modulada" em 
performances satíricas em locais públicos, declarações feitas por personalidades ou artistas em rádio, TV ou em mídias virtuais; artigos de opinião em jornais ou blogs, etc.

A segunda importante característica da teoria do frame goffmaniana decorre da importância que os proferimentos e enunciados comunicativos ostentam nos repertórios, na acepção de Charles Tilly da ação coletiva: reinvindicações por direitos e acesso a recursos em manifestações, passeatas, assembleias, greves, comícios, etc. O quadro conceitual das teorias clássicas da comunicação, baseado na tríade emissor-mensagem-receptor, seria precário para explicar as diferentes conformações do self em situações comuns da vida cotidiana, que envolvem dissimulações, omissões, ênfases, equívocos, fraudes, etc. E mais inadequado ainda para a análise de comunicações mediadas por artefatos eletrônicos (telefone, celular, teletransmissão, etc.) ou por computadores. O modelo do self como falante na comunicação, embora formulado numa época em que a telemática ainda estava no horizonte, contribui significativamente para a análise do quadro da ação coletiva. Na teoria do quadro de Goffman, o self como falante divide-se em quatro entidades diferentes: responsável, estrategista, animador e figura (cf. GOFFMAN, 1974, p. 5). Numa conversação normal, o próprio falante pode incorporar as quatro entidades, embora em muitos casos não o faça. Apresenta-se abaixo, para ilustrar o modelo, um trecho de mensagem enviada por correio eletrônico pela rede ativista Avaaz, em uma de suas campanhas, no dia 10 de junho de 2011:

2. Goffman faz aqui uma analogia entre as transformações em quadros da percepção e as mudanças de tonalidade na música. Para uma análise das analogias e do "modelo do estúdio" que Goffman constrói para explicar as transformações nos frames, consultar Nunes (2004, p. 175-180)

\begin{abstract}
A presidente Dilma deu o sinal verde para a construção da barragem de Belo Monte que destruirá enormes áreas da Amazônia. O cacique Raoni, chefe do povo caiapó, jurou lutar contra a usina até o fim. Vamos apoiá-lo como brasileiros e enviar uma inundação de telefonemas à presidenta Dilma, instando-a a impedir Belo Monte e salvar a Amazônia agora! [Destaques no original]
\end{abstract}

Na mensagem original, o texto reproduzido figura num quadro à direita de um texto explicativo mais extenso, como uma chamada jornalística em destaque com o conteúdo essencial acompanhada de uma contextualização factual informativa e argumentativa, mas também com apelo emotivo, dos atos contenciosos e das respostas do governo. O discurso indireto é utilizado em duas sentenças que remetem a ações efetivadas pela presidente Dilma e por seu oponente, em relação à construção da usina, o cacique caiapó Raoni. O efeito dos destaques em negrito nas duas frases sobre duas figuras proeminentes e representativas e suas ações, a aprovação pela chefe do poder executivo e sua contestação 
pelo representante chefe de um povo autóctone, simbolicamente relacionado à defesa do meio ambiente, é representar uma situação em que esses oponentes estejam um diante de outro, ou seja, uma situação interativa de confronto. 0 leitor é convidado e motivado a efetivar uma comunicação, ainda que intermediada por telefone, apoiando Raoni e sua causa, à presidente Dilma. Embora o chamado dificilmente seja atendido diretamente pela interlocutora desejada, o efeito físico e simbólico da estratégia é muito maior do que, por exemplo, uma petição assinada. Esse modelo de recurso, que podemos considerar já convencionalizado no repertório das redes de ativismo globais, geralmente não é aplicado no início de uma campanha. Em 2011, a Avaaz enviou quatro mensagens por correio eletrônico em sua campanha contra a construção de Belo Monte. As duas primeiras (13 e 17/01/2011) solicitavam a assinatura de uma petição à presidente Dilma contra a construção da barragem, logo após a autodemissão do presidente do Ibama e as duas últimas já solicitavam uma ação mais direta, a ligação telefônica ao gabinete da Dilma. Embora a mensagem esteja em nome de "Ben, Graziela, Alice, Ricken, Rewan e toda a equipe da Avaaz", pode-se conjeturar que eles sejam, mais propriamente, "animadores" de um texto em que a responsabilidade autoral não possa ser creditada totalmente a um ou a todos eles, mas já faça parte de um "repertório" da ação coletiva em redes ativistas globais, em que muitas outras pessoas trabalharam como "estrategistas", disponibilizando, inclusive, na própria mensagem, um vocabulário de motivos adequado para uma educada (pelo menos nessa fase da campanha), ainda que direta, franca e justificada, declaração de oposição à construção da obra:

Aqui estão algumas sugestões do que dizer - lembre-se de ser educado e respeitoso ao ligar.

- $\quad$ Eu estou ligando para insistir que o projeto da usina de Belo Monte seja interrompido

- $\quad$ Construir a usina destruirá 400.000 acres de floresta tropical Amazônica - um desastre para animais, plantas, e pessoas que dependem desse ecossistema sensível para viver

- $40 \%$ dos requisitos em saúde, educação, saneamento e proteção às terras indígenas não estão sendo garantidos pelo consórcio Norte Energia S.A. (NESA)

- Violência e especulação de terras cresceram nos últimos meses enquanto saúde, educação e saneamento são escassos na área de Belo Monte

- $\quad$ Nós devemos impedir Belo Monte agora, antes que o povo caiapó tome medidas desesperadas e arrisque suas vidas por causa da usina de Belo Monte 
Se continuarmos a análise, empregando o esquema goffmaniano das entidades do self, veremos que a estratégia emprega dois frames comunicacionais: o e-mail e o telefone. O vocabulário de motivos que constituem as "figuras" nos dois tipos de comunicação é praticamente o mesmo nos dois frames, ou seja, frases que relacionam efeitos políticos, econômicos, sociais ou ambientais à construção de Belo Monte como causa. Entretanto, quando as consideramos no contexto mais abstrato de um frame da ação coletiva, ou do protesto (cf. JONSTON \& NOKES, 2005), ocorre uma modulação, uma transformação do quadro, quando se faz a mesma solicitação de apoio diretamente à presidente Dilma, por telefone. Na "figura" do e-mail as proposições sociais, políticas, econômicas ou ambientais estão articuladas. Nas mensagens por telefone a Avaaz usa a estratégia operacional, mas também efetivamente simbólica, de separar essas proposições que, no entanto, estão articuladas ao self de cada interlocutor, que pode acatar a(s) que reconhece a valoriza mais. Porém, esse exercício de adequar o esquema de Goffman é apenas reconstrutivo para esse contexto, pois já há um desenvolvimento teórico e operacional da teoria do frame aplicada aos movimentos sociais ou ao frame de protesto.

O quadro conceitual do frame do protesto, um desdobramento emergente da análise interacionista dos movimentos sociais, nos levaria a interpretar a estratégia ativista que vimos tomando como exemplo como uma instância de alinhamento do frame (frame alignment). Snow e Benford conceituaram o alinhamento do frame como a associação de orientações interpretativas do indivíduo e do movimento social, de forma que algum conjunto de interesses, valores, crenças e atividades individuais e as atividades, metas e a ideologia da organização do movimento social sejam congruentes e complementares (1986, p. 464). No entanto, o frame da ação coletiva não apenas orienta crenças e sentidos que inspiram e legitimam as atividades e campanhas organizadas pelo movimento social, como querem as vertentes mais construcionistas das teorias de movimentos sociais, mas também constitui os próprios resultados desses significados compartilhados e em negociação (cf. SNOW \& BENFORD, 2000). Os autores, na esteira de Goffman, empregam diversas metáforas e analogias para identificar e caracterizar os processos de alinhamento no frame de protesto: fazer uma ponte (bridging), amplificação, extensão e transformação.

A "construção de pontes" compreende interligar diferentes frames que sejam ideologicamente congruentes, mas estejam estruturalmente desconectados em relação a determinado problema. Pode-se considerar como exemplo de alinhamento por bridging a relação entre o Movimento LGBT do Brasil e os núcleos de estudos pesquisa acadêmicos voltados à temática do gênero e da sexualidade. As redes de ativismo global, como a do exemplo aqui utilizado, efetivam intensivamente o bridging, principalmente por difusão em redes sociais virtuais, 
mas também por telefone, pela grande imprensa e até por formas tradicionais de comunicação, como panfletos, folders e correio.

A amplificação consiste em intensificar, esclarecer, estetizar ou revigorar crenças e valores existentes, pois os sentidos dos eventos e coisas que competem à questão social fundadora ficam, em geral, submersos pela indiferença, pela manipulação ideológica ou intencional por certos grupos. Entre os valores mais amplificados pelas organizações de movimentos sociais, estão a justiça, a igualdade, a solidariedade, a liberdade, a fraternidade, etc. A amplificação é usada com mais ênfase na organização de movimentos que foram ou são estigmatizados porque seus valores confrontem crenças e valores dominantes. Os movimentos que defendem a virgindade, por exemplo, amplificam o valor da "pureza" e restauram antigas práticas sociais que associavam a virgindade à defesa de outros valores, como a propriedade familiar, "moduladas" à moralidade de uma sociedade de consumidores, promovendo a venda de cartões ou vouchers de virgindade, ou eventos como o "baile da pureza", hoje comuns entre cristãos conservadores nos Estados Unidos.

O alinhamento por extensão requer que se ampliem os principais interesses na organização de um movimento social, incluindo aspectos e assuntos considerados como importantes para potenciais partidários. Alguns movimentos antirracistas, por exemplo, empregaram bandas de rock ou free jazz, organizando concertos e outros eventos para mobilizar a opinião pública e atrair partidários. Há até registros de extensão em que a estrutura primária de organização da percepção é a própria indústria do rock e o frame do protesto é como uma segunda lâmina do frame. É o caso do movimento Rock Against Racism (RAR), formado em 1976, em represália a uma declaração feita pelo guitarrista e compositor Eric Clapton ("keep Britain white"), declarando seu apoio ao político conservador inglês Enoch Powell, que criticava, com acento xenofóbico, a imigração em massa de estrangeiros para o Reino Unido. A organização iniciou a mobilização enviando cartas às principais revistas de música popular, marcando a identidade e conclamando a adesão a um movimento contrário ao racismo: "We want to organize a rank and file movement against the racist poison in music. We urge support for Rock Against Racism. P.S. Who shot the Sheriff, Eric? It sure as

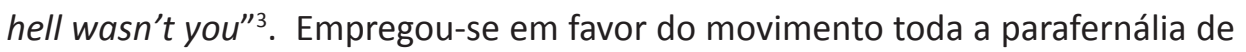
recursos que a indústria cultural do rock utiliza: adesivos, camisetas, pôsteres, faixas e um zine com o papel de comunicar as ideias do movimento. No entanto, a principal estratégia no frame foi a realização de concertos e passeatas organizadas com a Liga Antinazista e realizadas em 1977 e 1978, com performances de Elvis Costello, The Clash, Steel Pulse, X-Ray Spex e Tom Robinson, atraindo mais de 100 mil pessoas. (cf. MOORE \& ROBERTS, 2009). No Brasil há significativos exemplos similares de extensão, mas com estrutura primária
3. "Queremos organizar um movimento de base contra o veneno racista na música. Nós reivindicamos o apoio ao Rock Contra o Racismo. P.S. Quem matou o delegado? [alusão ao reggae $I$ shot the Sheriff, que ficou famoso na interpretação de Eric Clapton] Certamente não foi você". (tradução do autor) 
em movimentos culturais religiosos como os ministérios de música do movimento de renovação carismática, ligados à igreja católica, e os ministérios de louvor e o gospel evangélico, ligado a igrejas da linha neopentecostal.

Os processos de extensão no frame da ação coletiva têm como correlata uma ampliação interpretativa, hermenêutica, com base no estoque cultural disponível entre os agentes a serem cooptados. Por um lado, a extensão pode ser responsabilizada por uma perda no foco cultural que constitui o núcleo duro do frame, podendo levar à dispersão, mas por outro lado pode-se ganhar em ressonância. Essa metáfora sonora remete à efetividade do frame, ou seja, sua capacidade de sucesso para resolver as situações e dilemas sociais que conduziram à sua organização. O conteúdo do frame deve se relacionar à real situação de vida experimentada pelos seus potenciais agentes constituintes. Segundo Snow e Benford (1988), dois conjuntos de fatores que interagem explicam a variação em grau da ressonância do frame: a credibilidade do frame disponibilizado e sua relativa saliência. A credibilidade do frame, por sua vez, depende de sua consistência, da credibilidade empírica e da credibilidade dos articuladores e dos reivindicadores do frame. No que concerne à saliência em relação a alvos de mobilização, Snow e Benford identificam três dimensões: centralidade, comensurabilidade de experiências e fidelidade narrativa. A centralidade remete à importância que as crenças, valores e ideias associadas com o movimento apresentam para as vidas na população que é objeto da mobilização. Já a comensurabilidade tem a ver com o grau de congruência ou de ressonância dos enquadramentos do movimento com as experiências cotidianas e pessoais dos alvos da mobilização. Finalmente, a fidelidade narrativa se refere à ressonância dos enquadramentos em relação às narrativas culturais ou "mitos" dos alvos.

O construto de ressonância tem grande importância metodológica no campo das teorias do enquadramento de movimentos sociais. As variáveis associadas à ressonância constituem marcadores empíricos da efetividade do movimento e questões a respeito de validade, mensuração e reconhecimento intersubjetivo de sua pertinência são cruciais para a própria manutenção e desenvolvimento dessa nova abordagem dos movimentos sociais, pelo menos em relação às famílias teóricas tradicionalmente reconhecidas: da mobilização de recursos, do processo político e dos novos movimentos sociais. Nookes e Johnston (2005) reconhecem, no que concerne à ressonância, que há, na prática, pouco suporte empírico para sustentar tantas distinções conceituais como as estabelecidas por Snow e Benford e organizam uma tabela simplificada sobre as variáveis que afetam a ressonância de um frame: 


\begin{tabular}{|c|c|c|}
\hline $\begin{array}{l}\text { Produtores de um } \\
\text { frame } \\
\text { Empreendedores do } \\
\text { movimento }\end{array}$ & $\begin{array}{l}\text { Receptores de um } \\
\text { frame } \\
\text { A audiência-alvo }\end{array}$ & $\begin{array}{l}\text { Qualidades de um } \\
\text { frame } \\
\text { Conteúdo esquemático }\end{array}$ \\
\hline $\begin{array}{l}\text { Credibilidade dos pro- } \\
\text { motores: organização } \\
\text { profissionais, creden- } \\
\text { ciais e expertise }\end{array}$ & $\begin{array}{l}\text { Orientações ideológicas } \\
\text { (o alvo da construção } \\
\text { de pontes como alinha- } \\
\text { mento do frame) }\end{array}$ & $\begin{array}{l}\text { Compatibilidade cultural: } \\
\text { a centralidade avaliativa } \\
\text { do frame, sua fidelidade } \\
\text { narrativa e slogans (am- } \\
\text { plificação) }\end{array}$ \\
\hline $\begin{array}{l}\text { Autoridade carismática: } \\
\text { qualidades pessoais ra- } \\
\text { ras e únicas de um líder } \\
\text { do movimento }\end{array}$ & $\begin{array}{l}\text { Orientações demográfi- } \\
\text { ca, atitudinal e moral (o } \\
\text { propósito da extensão } \\
\text { e da transformação do } \\
\text { frame) }\end{array}$ & Consistência do frame \\
\hline $\begin{array}{l}\text { Orientação estratégica } \\
\text { ou do marketing (ou } \\
\text { cinismo) }\end{array}$ & & $\begin{array}{l}\text { Relevância (incluindo } \\
\text { credibilidade empírica } \\
\text { e comensurabilidade de } \\
\text { experiências) }\end{array}$ \\
\hline
\end{tabular}

As estratégias, programas e valores que a organização do movimento social promovem devem ressoar positiva ou negativamente em relação a estilos de vida, rituais de interação e quadros interpretativos existentes. Quando ocorre uma contradição ou antítese entre o novo e o velho quadro da percepção, as crenças discrepantes devem ser reenquadradas e os velhos sentidos alijados, o que configura uma transformação no quadro, último processo estratégico de alinhamento. Apesar de sua pertinência ser reconhecida na família teórica do frame da ação coletiva, há escassa sustentação empírica de sua realização sistemática na agenda dos movimentos sociais, bem como na análise empírica de casos correlatos (cf. SNOW \& BENFORD, 2000).

Dentre os principais conceitos das teorias do frame da ação coletiva ou do protesto, figura o de "quadros mestres" (master frames), tipos de quadros de escopo muito amplo, que funcionam como uma espécie de algoritmo que constrange as orientações e atividades de outros movimentos. Segundo Snow e Benford (1992), "os quadros mestres estão para os movimentos de ação coletiva específicos assim como os paradigmas estão para as teorias finalizadas". A possibilidade de agregar, de alguma forma, os movimentos sociais já estava presente no próprio Blumer, mentor do interacionismo simbólico, quando sugeria que os movimentos sociais gerais são tributários de um tipo de inquietude social. A ideia de uma motivação unificadora para os movimentos sociais foi retomada, com variações, por outros autores, como Orrin Klapp (1972), correntes de inquietude; McCarthy e Zald (1977), organização; Sidney Tarrow (1983), 
ciclos de protesto. Poucos frames de protesto foram considerados como suficientemente amplos em termos de abrangência interpretativa, flexibilidade e ressonância cultural para operar como quadros mestres. Pode-se considerar, se nos pautarmos no caso brasileiro, que os frames de direitos sociais, de injustiça, de direitos ambientais atenderiam a esses requisitos, embora a literatura aponte outros exemplos de master frames (escolha, pluralismo cultural, terrorismo sexual, oposicional, hegemônico e "retorno à democracia") (cf. SNOW \& BENFORD, 2000).

\section{Considerações finais}

A breve reconstrução aqui realizada da influência do interacionismo simbólico, de Blumer a Goffman, na elaboração e desenvolvimento da teoria do frame da ação coletiva ressalta o potencial heurístico de seu emprego em nível metateórico em relação às famílias de teorias de movimentos sociais já reconhecidas. O frame é um esquema interpretativo que orienta a percepção e a experiência dos indivíduos que, atuando seletivamente, identifica, pontua e codifica objetos, situações, experiências, eventos e sequências de ações presentes e pretéritas. Torna-se importante na análise da ação coletiva, já que é compartilhado por um certo número de indivíduos, que passam a direcionar suas orientações cognitivas, em diferentes níveis da experiência, no sentido de um comportamento social padronizado e orientado a certos objetivos. No entanto, a eficácia na organização de um movimento social não depende apenas da natureza do trabalho interpretativo, dos recursos da organização ou da relevância do conteúdo do frame e seus vocabulários de motivos em relação às experiências vividas pelos alvos da mobilização, mas também pela recepção do frame. Em outras palavras, a ressonância do frame da ação coletiva está relacionada com sua recepção, com fatores externos à produção do frame que remetem ao perfil social e atitudinal dos prováveis constituintes, além de suas orientações ideológicas. Ainda assim, pode-se considerar que a teoria do frame privilegia um tipo de percepção e orientação seletiva do self diante de um estoque cultural compartiIhado desigualmente graças às distinções de classe ou posição social. Portanto, torna-se benvinda a incorporação de elementos da teoria do processo político, como a consideração estratégica da estrutura das oportunidades políticas. A seletividade para acentuar eventos, motivações ou situações e a coordenação desses traços escolhidos com os tipos de recursos para reivindicação empregados não dependeria apenas do alinhamento do frame, mas também de constrangimentos ou incentivos das interações entre os ativistas e os detentores do poder, bem como do contexto histórico social e do regime político. 
A popularização da perspectiva do enquadramento na análise dos movimentos sociais, evidenciada pelo número crescente de papers, artigos e pesquisas empíricas produzidas com base na teoria, além do crescimento significativo de citações dos artigos considerados fundadores ou seminais na perspectiva pode, em parte, ser explicada pelo potencial heurístico e a compatibilidade com a extensão do frame da ação coletiva, tanto em seu emprego reflexivo da própria orientação do movimento social, quanto no sentido epistemológico da produção de um conhecimento científico sobre a intervenção social medida pela organização de um movimento direcionado pelo frame. A extensão epistemológica do frame da ação coletiva amplia sua abrangência não somente a movimentos de escassa motivação política, mas também a mobilizações que não seriam consideradas movimentos sociais, no sentido de ações coletivas realizadas, pelo menos em seu início, com baixo grau de organização e fora da esfera institucional, principalmente em relação ao Estado ou ao governo. Estratégias de mobilização empregadas por órgãos estatais ou programas sociais governamentais têm sido objeto de análises por intermédio da teoria do frame da ação coletiva, sob a rubrica de "frames oficiais", como a pesquisa sobre o enquadramento construído pelo FBI da "ameaça comunista" em Hollywood, desenvolvida por John A. Noakes (2005).

Certamente, a ação de programas de desenvolvimento econômico como os Arranjos Produtivos Locais ou a intervenção da Secretaria da Economia Solidária no associativismo cooperativista, ambas no Brasil, constituiriam bom exemplos para estudos de caso da organização de frames de ação coletiva.

Por outro lado, a própria mídia ganha efetividade na organização e efetivação de frames de ação coletiva. Aliás, o interesse da perspectiva pela ação da mídia não é recente. William A. Gamson (1992) ressaltava, diferentemente de outros teóricos em sua época, a importância do estudo do discurso midiático. Gamson considera a mídia não só como agência central na produção do significado cultural, mas também como um dos pontos de convergência dos movimentos sociais para mudar a política pública ou as percepções. Seus trabalhos empíricos contribuem para estudo da opinião pública e consistem em análises de transcrições de discussões realizadas em pequenos grupos. Também se distinguiu por propor um método de identificação e codificação de quadros, sinalizando para a possibilidade de uma análise quantitativa do frame, empregando softwares estatísticos para "análise do conteúdo" de textos. A teoria de Gamson constitui a base para uma metodologia da análise do frame proposta por Hank Johnston (1995), que consistia, grosso modo, em submeter uma base empírica de textos falados e escritos de movimentos sociais a uma microanálise de frames, vistos como resultado de um planejamento estratégico, mas também de correntes culturais de âmbito internacional. 
A leitura "engajada" feita por autores como Snow e Benford, Gamson e Johnston da análise do frame recebeu críticas, principalmente em razão da dificuldade em distinguir os conceitos de quadro e de estruturas ideológicas. Há também o que poderíamos aproximar de um problema da base empírica na teoria do frame, com reflexos na análise dos movimentos sociais. Qualquer transformação no quadro da experiência e percepção, como as modulações (keyings) e fabricações (fabrications), analisadas por Goffman, tem por base estruturas primárias de percepção de atividades (primary frameworks), como o quadro que torna inteligível uma conversa entre duas pessoas. Seria possível, contudo, considerar tal quadro como primário sendo que podemos empregar na conversação comum termos ou expressões empregados em comunicações intermediadas por computadores, por exemplo? Não há ainda respostas satisfatória a essas questões metodológicas, embora sua própria formulação e tratamento em alguns artigos (e.g., OLIVER \& JOHNSTON, 2005; SNOW, 2004) já indique, em grau significante, o aprimoramento da perspectiva e, por outro lado, o início de sua crítica interna.

Abstract: The frame theory, developed by Goffman in Frame Analysis (1974), has been applied in theoretical guidance and in methodological analysis of new social movements. The aim here is to reconstruct the usage of the frame concept and other elements of interactionist sociological tradition on the analysis, made by authors as Gamson (1988), Snow \& Benford (1988), Johnston (2005), of the collective action in social movements. It can be stated that the analytical fruitfulness of the collective action frame, not only to investigate mobilizations at first realized with low organization level and out of the institutional sphere, but also in the analysis of strategies applied by state organizations or government social policies.

Keywords: Social Movements, Frame Analysis, Goffman, Collective Action, Symbolic Interactionism.

\section{Referências}

ALONSO, Angela. "As teorias dos movimentos sociais: um balanço do debate". Lua Nova, n. 76, 2009, p. 49-86.

BATESON, Gregory. "A theory of play and phantasy", In: Steps to an echology of mind. New York: Ballantine Books, 1972 [1954].

BENFORD, Robert D. "You could be the hundredth monkey': collective action frames and vocabularies of motive within the nuclear disarmament movement". Sociological Quarterly, v. 34, n. 2, 1993, p. 195-216.

BLUMER, Herbert. "Collective behavior", In: PARK, Robert (Ed.). An Outline of the Principles of Sociology. New York: Barnes and Noble, 1939. p. 221-280. 
BLUMER, Herbert. Simbolic Interactionism. Perspective and Method. Englewood Cliffs: Prentice-Hall, 1969.

GAMSON, William A. Talking Politics. Boston: Cambridge University, 1992.

GILBERT, Margareth. "Rationality in Collective Action". Philosophy of the Social Sciences, v. 36, n. 1, March, 2006, p. 3-17.

GOFFMAN, Erving. "A situação negligenciada", In: RIBEIRO, Bianca T.; GARCEZ, Pedro M. (Orgs.) Sociolinguística Interacional. 2ed. São Paulo: Loyola, 2002. p. 13-20.

GOFFMAN, E. Frame analysis. New York: Harper, 1974.

GOHN, Maria da G. Novas teorias dos movimentos sociais. São Paulo: Loyola, 2008.

HABERMAS, Jurgen. "Un informe bibliográfico: la lógica de las ciencias sociales.", In: La lógica de las ciencias sociales. Trad. Manuel Jiménez Redondo. Madrid: Tecnos, 1996 [1967], p. 81-275.

. The theory of communicative action - Reason and the rationalization of society. Boston: Beacon, 1984 [1981].

. "New social movements". Telos, New York, n. 49, 1981.

. The theory of communicative action - Lifeworld and system: a critique of funcionalist reason. Boston: Beacon, 1987 [1985].

JAMES, William. Principles of Psychology, v. 2 New York: Dover Publications, 1950 , cap. 21, p. 283-324.

JOHNSTON, Hank. "A methodology for frame analysis: from discourse to cognitive schemata". Social movements protest and contention, v. 4, 1995, p. 217-246.

JOHNSTON, Hank \& NOAKES, John A. "Frames of protest: a road map to a perspective", In: JOHNSTON, Hank \& NOAKES, John A (Ed.). Frames of protest. Social movements and the Framing Perspective. Lauham: Rowman \& Littlefield, 2005. p. 1-29.

KLAPP, Orrin. Currents of Unrest: An Introduction to Collective Behavior. New York: Holt, Rinehart and Winston, 1972.

LAKATOS, Imre. The methodology of scientific research programs. Cambridge: Cambridge University, 1978. 
LINDESMITH, Alfred R., STRAUSS, Anselm L. \& DENZIN, Norman (Orgs.) Social Psychology. 6. ed. Englewood Cliffs, NJ: Prentice Hall, 1988.

LYMAN, Stanford M.; SCOTT, Marvin B. "Accounts", In: A sociology of the absurd. 2ed. Dix Hills: General Hall, 1989 [1968]. p. 112-132.

MCCARTHY, John D. \& ZALD, Mayer N. "Resource mobilization and social movements: a partial theory". American Journal of Sociology, v. 82, n. 6, 1977, p. 1212-1241.

MEAD, George H. Mind, self and society from the standpoint of a social behaviorist. Chicago: University of Chicago, 1932. Disponível on-line: <http://www. brocku.ca/MeadProject/Mead/pubs2/mindself/Mead_1934_toc.html> Acesso em 10/07/2011.

MELUCCI, Alberto. A invenção do presente: movimentos sociais nas sociedades complexas. Petrópolis: Vozes, 2001.

. "The new social movements: a theoretical approach." Social Science Information, 1981, v. 19, n. 2.

MOORE, Ryan \& ROBERTS, Mike. "Peace Punks and Punks against Racism: Resource Mobilization and Frame Construction in the Punk Movement". Music and Arts in Action, San Diego, v. 2, n. 1, 2009. Disponível em < http://musicandartsinaction.net/index.php/maia/article/view/punkmovements>. Acesso em $15 / 07 / 2011$.

NUNES, Jordão Horta. O interacionismo simbólico e a dramaturgia: a sociologia de Goffman. São Paulo: Humanitas/Goiânia: Editora da UFG, 2004.

OLIVER, Pamela E. \& JOHNSTON, Hank. "What a good idea! Ideologies and frames in social research", In: JOHNSTON, Hank; NOAKES, John A (Eds.). Frames of protest. Social movements and the Framing Perspective. Lauham: Rowman \& Littlefield, 2005. p. 185-203.

SCHUTZ, Alfred. “On multiple realities”, In: Philosophy and Phenomenological Research, V (1945):, p. 533-576.

SEARLE, John R. The construction of social reality. London: Penguin, 1995.

SNOW, David A. \& BENFORD, Robert D. "Master Frames and Cycles of Protest", In: MORRIS, A. D. \& MUELLER, C. M. (Ed.), Frontiers in Social Movement Theory. New Haven: Yale University, 1992. p. 133-155. 
SNOW, David A. \& BENFORD, Robert D. "Framing processes and social movements: an overview and assessment". Annual Review of Sociology, 2000, n. 26, p. 611-29.

SNOW, David A. \& BENFORD, Robert D. "Ideology, frame resonance, and participant mobilization”, In: KLANDERMANS, B., KRIESI, H.. \& TARROW, S. (Ed.) International Social Movement Research: V. 1. London: JAI Press, 1988.

SNOW, David A. et al. "Frame Alignment Processes, Micromobilization, and Movement Participation". American Sociological Review, v. 51, n. 4, 19, 1986, p. 464-481.

SNOW, David. A. "Framing Processes, Ideology, and Discursive Fields", In: SNOW, D. A.; SOULE, S.A. \& KRIESI, Hanspeter (Ed.). The Blackwell Companion to Social Movements. Oxford: Blackwell, 2004. p. 380-411.

STRAUSS, Anselm L. Espelhos e máscaras - A busca de identidade. São Paulo: Editora da USP, 1999 [1959].

TARROW, Sidney. Struggling to Reform: Social Movements and Policy Change during Cycles of Protest. Ithaca, N.Y.: Western Societies Program, Cornell University, 1983.

TILLY , Charles. From mobilization to revolution. Newberry Award Records, 1978. TOURAINE, Alain. La voix et le regard. Paris: Seuil, 1978. 